\title{
How to Motivate our Students to Study Physics?
}

\author{
Renata Holubova \\ Department of Experimental Physics, Science Faculty, Palacky University, Czech Republic
}

Copyright (C) 2015 by authors, all rights reserved. Authors agree that this article remains permanently open access under the terms of the Creative Commons Attribution License 4.0 International License

\begin{abstract}
The main issue of this paper is the discussion around the question "How can we teach and motivate the why-generation learners and the generation $\mathrm{Z}$ learners?". The aim of our project was to find out teaching and learning methods that teachers and learners can use in 21 st century classroom. Strategies how to engage gen $\mathrm{Y}$ and gen $\mathrm{Z}$ learners in the learning process should be found. During our research various methods were used: problem based learning, project based learning, team work, inquiry based learning, interdisciplinary approach, experiments - from very simple and low cost experiments to computer based experiments and remote laboratories. It was found out, that generation $\mathrm{Y}$ so as gen $\mathrm{Z}$ learners can be motivated by various instructional methods based on their own activity. Their own doing seemed to be more important for them than learning itself. It is necessary to use educational materials including charts, graphic presentations, cartoons. Also it was found out that a very useful tool for our students can be the mind mapping. Mind maps and concept maps are not common during students instruction at secondary and high schools in the Czech republic. We prepared a set of concept maps on the basis of high school physics textbooks, from mechanics, molecular physics, via electricity and magnetism to optics, and nuclear physics. In this paper the outcomes of our project will be presented so as some examples of interdisciplinary modules that have been prepared - "real-world" physics modules with everyday life problems that can be integrated into the high school curriculum physics (physics in the kitchen, crime scene investigation, environmental physics), non-traditional experiments, properties of non-Newtonian liquids (experiments with dilatant fluids, oobleck, the suspension of starch, the Weissenberg effect, Barus effect, the Kaye effect), modern physics - nanotechnology (cooperation with the Regional Centre of Advanced Technologies and Materials - a faculty establishment). The findings of this project are incorporated into the subject "Didactics of Physics" in the undergraduate physics teacher study programme at the Faculty of Science.
\end{abstract}

Keywords Millennials, Teaching Methods, Concept Maps, Motivation, Interdisciplinary Relations

\section{Introduction}

The issue of teaching Generation $\mathrm{Y}$ has been discussed previously [1]. The why - generation, called also Y gen, Millennial generation was born in 1980-2000. The generation $\mathrm{Y}$ students learn and study in such a different way as the previous gen $\mathrm{X}$ did. They have other characteristics than generation $\mathrm{X}$ that are important and affect their learning in positive and negative ways. Gen $\mathrm{Y}$ students are characterized as www users and technology users. Gen $\mathrm{Y}$ is powerful and able to change the world. They want to learn with technology, online and doing thing that matter - this is almost important for them. Being on line is necessary for learning, research, socializing. Learners born in 1995-2012 are generation $\mathrm{Z}$ kids. Their current population is about 23 million. We know only a little about this new generation. Currently, we speak not only of generation Y, but also the newly emerging generation $Z$. A few years ago the debate about whether the use of digital technology does not digitize the children themselves has been launched, triggered by the publication of books by Don Tapscott in 1998. For example we can point out his book "Growing Up Digital : The Rise of the Net Generation". It stated, among other things, that from the generational point of view, children are "ahead" of their parents right in the use of digital technology, which is the key factor in today's society. Prensky [7] divides the generation into digital natives and digital immigrants. Digital natives are identified as having "radically different way of thinking, processing information and learning new things." Compared to them, "digital immigrants have very little understanding of these new skills that the natives have cultivated by years of testing and interaction. These skills are something almost foreign to immigrants who learn slowly, step by step, one by one, individually, and above all, with a straight face." Prensky therefore is one of the main promoters of leaving the traditional method of individualized learning. Primacy should play class digitization, linking play with learning, increasing interactivity in the classroom. The results stated below show the inability of schools and teachers to adapt to the way of students' thinking and their way of information processing (see results of Czech pupils' reading literacy in PISA (Programme for International Student Assessment)). The new generation of our kids, the generation $\mathrm{Z}$ leaners are 
even more Internet savvy than gen $\mathrm{Y}$ was. As written on Education views [13], the following result can be shortly summarized: Baby boomers changed politics, Gen X changed family, Gen $Y$ changed work and Gen $Z$ will change education.

Today's elementary and middle schools are becoming better and better equipped with information and communications technologies (ICT). Some teachers perceive this fact very positively and try to engage digital media into educational process. Nowadays it is also agreed in public that today's schools cannot teach our kids just using chalk and blackboard. But only up to date school equipment and modern technology will not improve the quality of teaching. Use of multimedia is not the only way how to motivate students in the classroom. The technology has the potential to modernize teaching and can provide a support, in particular, to the constructivist approach of acquisition of skills and knowledge. Contribution lies mainly in the fact that modern technology will accelerate and automate some of the activities that are tedious, repetitive. The teacher gets more time for the use of activation methods of teaching. Many teachers involves ICT into teaching just because they know that students enjoy using the computer. Often they are not able to exploit the potential that digital technologies have given to teaching. As states Zounek [11] the issue is a didactic effectiveness: the children are happy when they can be at their computer, but the teacher, because of "packed curriculum", cannot afford it too often. Taking into consideration the huge investment that involves schools technologization, such perception of ICT as a teaching brake seems somewhat paradoxical. It often indicates that teachers are poorly prepared to use ICT technology for didactic purposes. It therefore stresses the baseline at today's school operation due to the link teacher - student and motivation students can monitor digital technology, the teacher's skills to operate ICT is something rather different from that to be used it in teaching.

The problem often lies in a small compendium of teacher about how to use ICT in teaching different subjects.

\section{Research Area}

The aim of the research was to analyse teaching Physics provided by different teachers in different schools. Our project was intended as a follow-up research to the activity of the Educational Research Centre in Brno. Between 2004-2007 this centre carried an extensive research on the second level of elementary schools using video-analysis (Janík 2009). Goals of the monitoring have been, for example: organizational forms of teaching, stages of teaching, teaching materials and media used in education, opportunities of verbal expression offered by the instructions. The survey showed that average 14 minutes of the teaching class (of 45 minutes) were devoted to talking with students, 10 minutes - to presentation of a new material, 4.5 minutes to independent students' work and 3.75 minutes to work in pairs or groups. Most of the teaching hours were rather focused on teachers. In the teaching hours very little time was devoted to a recap of the curriculum. As to the usage of modern tools and technologies in more than $40 \%$ of teaching classes no medium was used. Most experiments were carried out in the traditional way. In the analysis of verbal expression, it was found out that the average number of teacher's words was 2976, while student's - 616 [4].

Our own research was also focused on the study of physics' lessons - the design of the lesson - realized by teachers with different specializations and different lengths of teaching experience. In the framework of our investigation auditions at 10 different elementary schools (including private ones and for students with special ADHD disorder - Attention Deficit Hyperactivity Disorder) in cities with different number of inhabitants were carried out.

During the observation period the following indicators were considered:

- teachers' activity - goal setting (e.g., using active verbs " define ", "prove"),

- timing goals, structure of the lesson, work with students, discipline

- methods

- teaching aids

- the use of ICT

- lesson development and environmental conditions.

Findings showed that teaching in those schools is conducted in the traditional way. The goal of the teaching was formulated, in $40 \%$ cases, immediately after the start of the teaching hour and mostly using active verbs. Explanation of the new material was provided by a teacher, the general criteria of correctness and adequacy of verbal expression being held. Teachers were able to ask students factually correct and understandable questions, involving the whole class into the dialogue. Unfortunately, these activating teaching methods were used in a small part of the lesson. An interesting and intriguing explanation of the material appeared only in $30 \%$ of the lessons. Discipline was maintained by warning ( $50 \%$ of cases), shouting, slamming textbook, referring to the reduction of classification. All teachers used various equipment during teaching computer with a data projector (in two classes), in one class video, mostly used equipment were classical educational aids, sometimes - non-traditional experimental aids (PET bottles). Interesting was the lesson in the classroom with children with ADHD. These children tend to disturb, to be in the spotlight, talking fast. On the other hand, these children were very active in learning, in case of making a mistake they were trying to find other solution, they discussed the problems. In the rest of schools we visited the majority of students was passive, unwilling to answer or seek for new solutions. One of the most important conclusions of this research is that in addition to the use of data projector and, in one case, an interactive whiteboard, the method of teaching has not changed. Even in today's school prevails classic lesson structure without the use of ICT that does not conform 
to the requirements for the education of students' generation $\mathrm{Y}$ and generation $\mathrm{Z}$. The same trend persists in a large number of secondary schools, where only few teachers use the potential of problem and project based learning, teamwork, interdisciplinary relations and computer controlled experiments.

\section{Output of Research}

As a help to secondary school teachers a set of concept maps, based on our findings, has been developed. These maps were created according to physics textbooks used in secondary schools in the Czech Republic. Due to the Generation $\mathrm{Y}$ way of learning the mentioned structuring concepts were developed as a tool to increase the quality of learning. Students can also create conceptual maps in free available programs and take advantage of ICT usage. The conceptual structure can also indicate the current state of students' knowledge and can be kept supplemented and refined. It also allows variable use of concept maps in teaching: a) Comprehensive concept map - is created by the teacher, includes the basic concepts and relationships between them

b) Teaching tool - a graphical interpretation of the curriculum, it is possible to use only a part of the map relating to the appropriate section of the curriculum

c) Learning aid - students create their own maps.

The map can include concepts from everyday life and other natural sciences. The map is not correct or incorrect, it indicates the current state of student' knowledge and understanding of the concepts discussed.

Concept maps, which should serve as a diagnostic tool, can be evaluated by a teacher using the following criteria: complexity, inclusion of basic concepts, and existence of meaningful relationships between concepts.

During the course Didactic of Physics students - future teachers of physics are getting familiar with this tool and learn how to create and evaluate conceptual maps. Software that was used - CmapTools, SMARTIdeas software 5.1, mind maple, free mind.

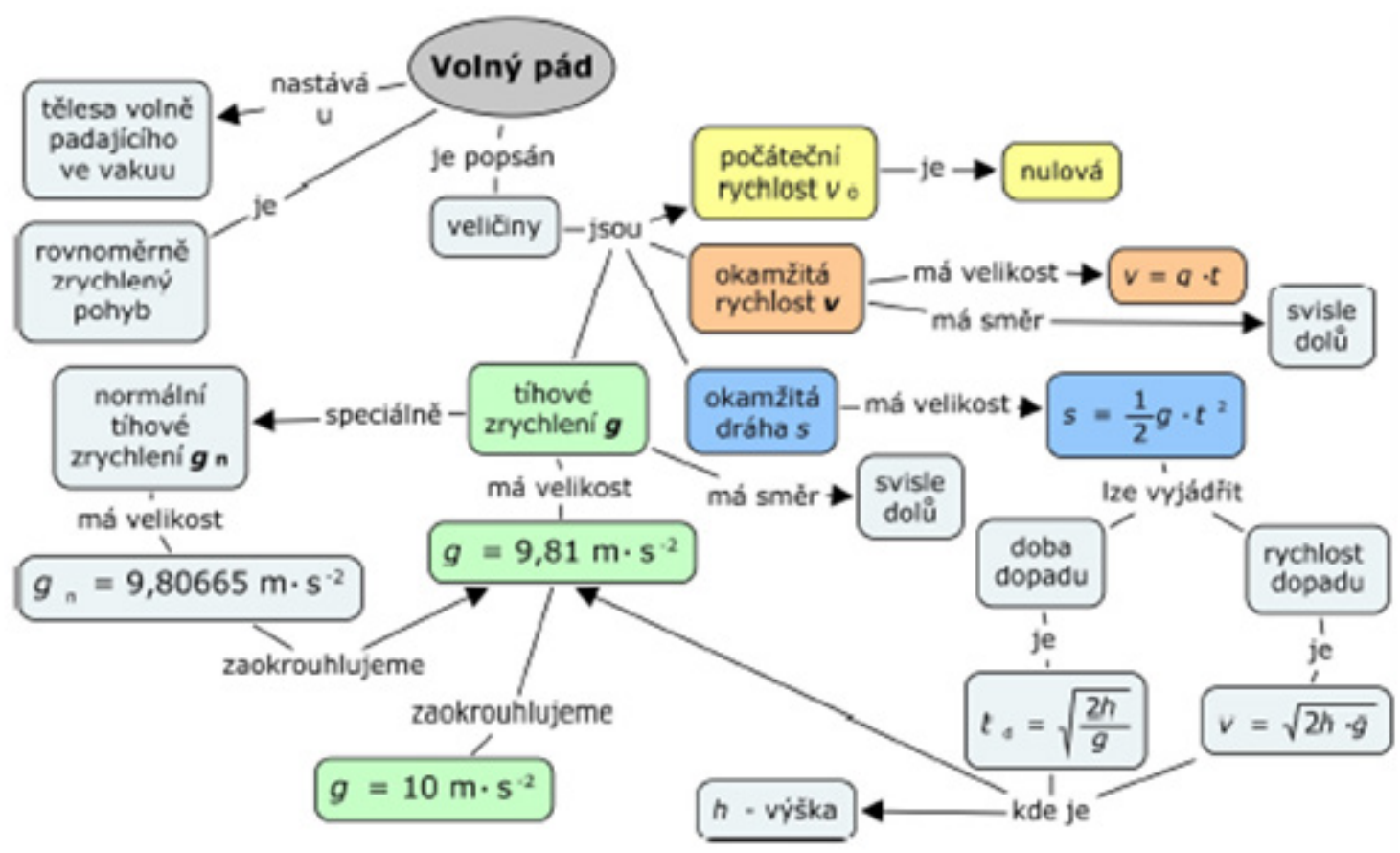

Figure 1. Concept map - example (free fall) 


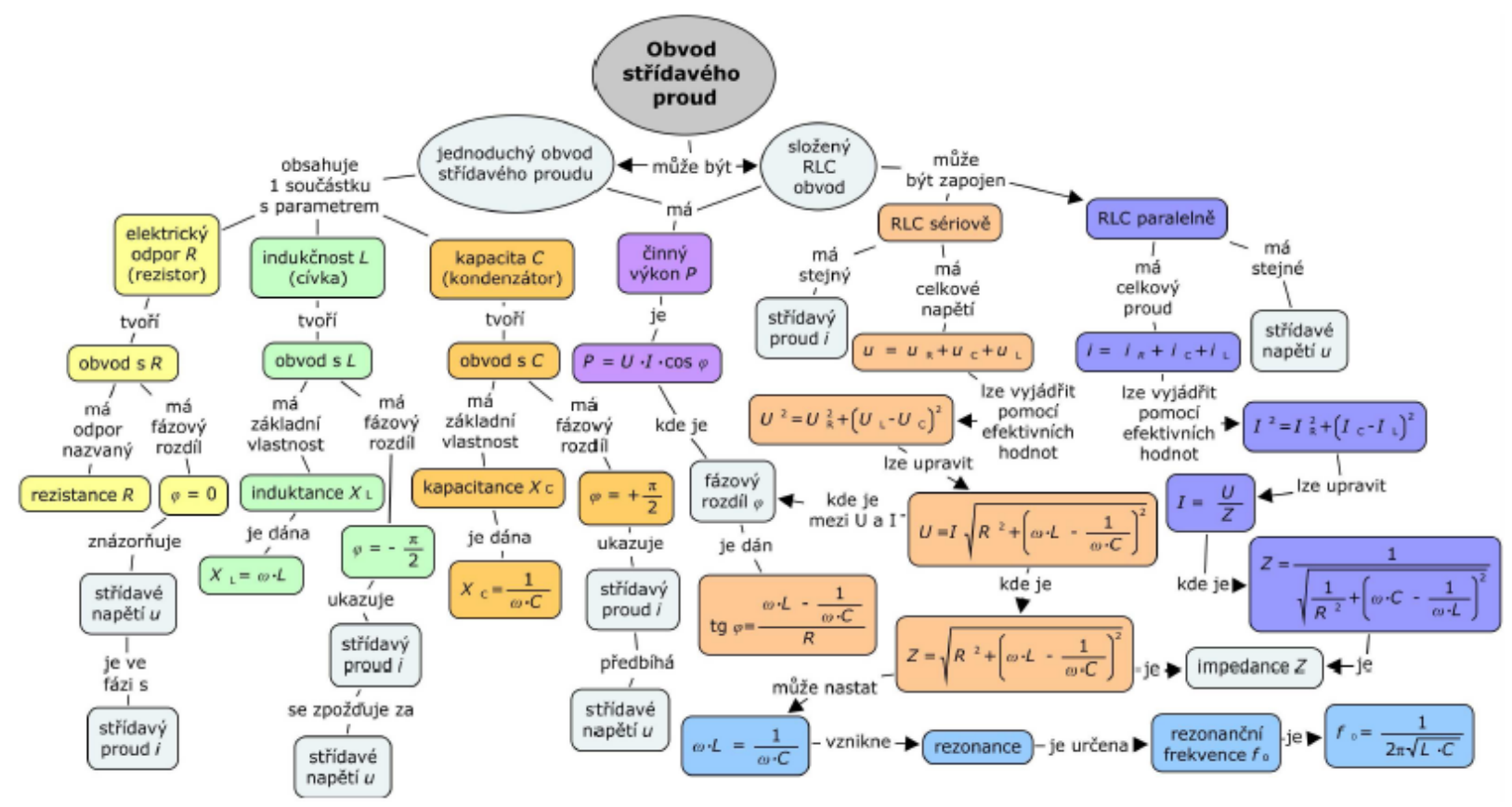

Figure 2. Concept map - example (circuit of alternating current)

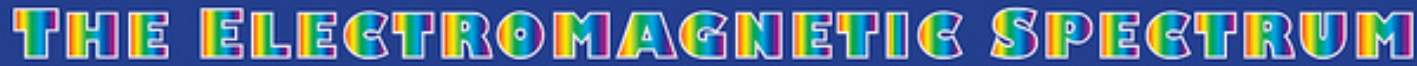

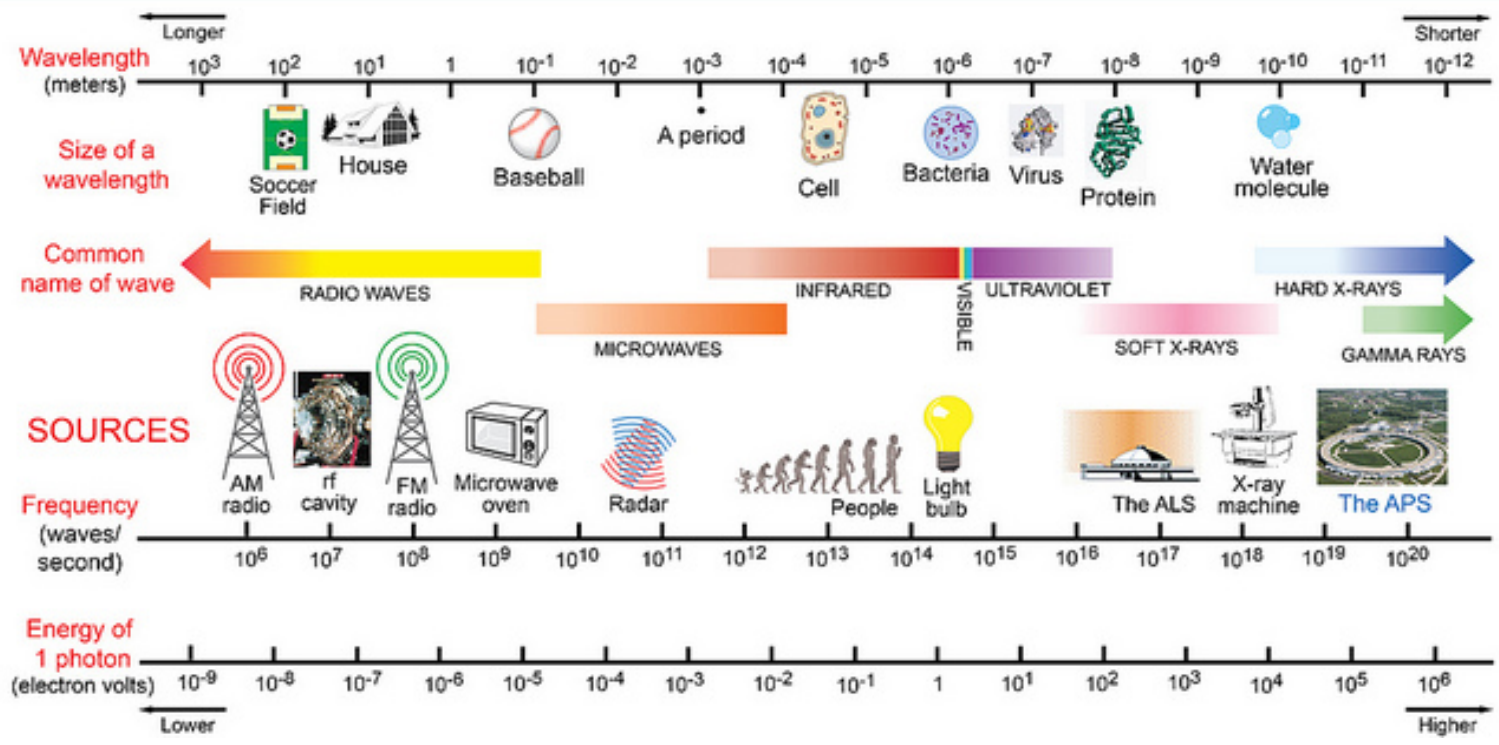

(https://c1.staticflickr.com/7/6142/5940581568_1db150f055_z.jpg)

Figure 3. The electromagnetic spectrum

\section{Upgrading existing modules}

As stated in the paper at the conference GIREP 2013(GIREP- International Research Group on Physics Teaching) [1], to help our teachers (so as to motivate students) modules that use inter-disciplinary links were prepared. The application of natural sciences in everyday life and also the use of modern technology is underlined to. Primary and secondary schools expressed strong interest, in particular, to the presentation of the modules Physics and Criminology, Culinary Physics and Environmental Physics.
Modules have been presented at more than 50 schools in the country. Modules content has been upgraded - it was extended by using of modern technology - thermal imagers and digital microscope, including proposals for series of experiments with these tools.

\section{Examples of new topics}

Thermal imager - thematic units in the high school physics curriculum: electromagnetic radiation, optics - blackbody radiation. 


\section{Basic knowledge:}

Thermography is a measuring method, which allows you to display graphically the temperature on the surface of the object being tracked. Infrared radiation is emitted by all bodies whose temperature is above absolute zero.

Relations, which are used in thermography and which are part of the school curriculum:

\section{- Planck's law}

Planck's law expresses the dependence of the intensity of blackbody radiation on the thermodynamic temperature and wavelength. The claim is based on the observation that each body having a surface temperature above absolute zero emits electromagnetic radiation with a wavelength corresponding to its temperature.

$$
W_{\lambda b}=\frac{2 \pi h c^{2}}{\lambda^{5}\left(e^{\frac{h c}{\lambda k T}}-1\right)} \cdot 10^{-6}\left[\mathrm{~W} \cdot \mathrm{m}^{-3}\right]
$$

where $W_{\lambda b}$ is the spectral density of the intensity of black body radiation at wavelength $\lambda, c$ is the speed of light $\left(3 \cdot 10^{8}\right.$ $\mathrm{m} \cdot \mathrm{s}^{-1}, h$ is Planck's constant $\left(6.626 \cdot 10^{-34} \mathrm{~J} \cdot \mathrm{s}\right), k$ is Boltzmann's constant $\left(1.381 \cdot 10^{-23} \mathrm{~J} \cdot \mathrm{K}^{-1}\right), T$ is absolute temperature of the black body $[\mathrm{K}]$ and $\lambda$-wavelength $[\mathrm{m}]$.

- Wien's displacement law

The Law describes the change in wavelengths at which blackbody energy is radiated in dependence on the change of thermodynamic temperature $\lambda_{\max }=b / T[\mathrm{~m}]$, where $\lambda_{\max }$ is the wavelength of maximum emission, $T$ is the thermodynamic temperature of a black body, and $b$ is Wien constant $\left(b=2.898 \cdot 10^{-3} \mathrm{~m} \cdot \mathrm{K}\right)$.

\section{- Stefan - Boltzmann law}

Stefan- Boltzmann law describes the overall intensity of blackbody radiation. The law says that the intensity of the radiation increases in direct proportion to the fourth power of the thermodynamic temperature of the radiating body. However, in real conditions we cannot meet with absolutely black body; hence we need to complement Stefan Boltzmann relation with the emissivity $\varepsilon$ of the body.

$$
W_{b}=\varepsilon \sigma T^{4} \quad\left[\mathrm{~W} \cdot \mathrm{m}^{-2}\right],
$$

where $W_{b}$ is the spectral density of the intensity of black body radiation, $\varepsilon$ is body emissivity, $\sigma$ is the Stefan Boltzmann constant $\left(\sigma=5.670 \cdot 10^{-8} \mathrm{~W} \cdot \mathrm{m}^{-2} \cdot \mathrm{K}^{-4}\right)$ and $T$ is the thermodynamic temperature $[\mathrm{K}]$.

\section{- Thermo gram}

The output from the thermal imaging camera is an infrared image called a thermo gram, or thermal image. Thermal imagers allow the user to determine the temperature at each point of the thermo gram. Infrared light is invisible to the human eye, for this reason, infrared images are visualized in the visible spectrum using different colour palettes, which are assigned to each of different colour temperatures. Among the most frequently discovered palette colours in thermography are: polar ice, iron, and rainbow.
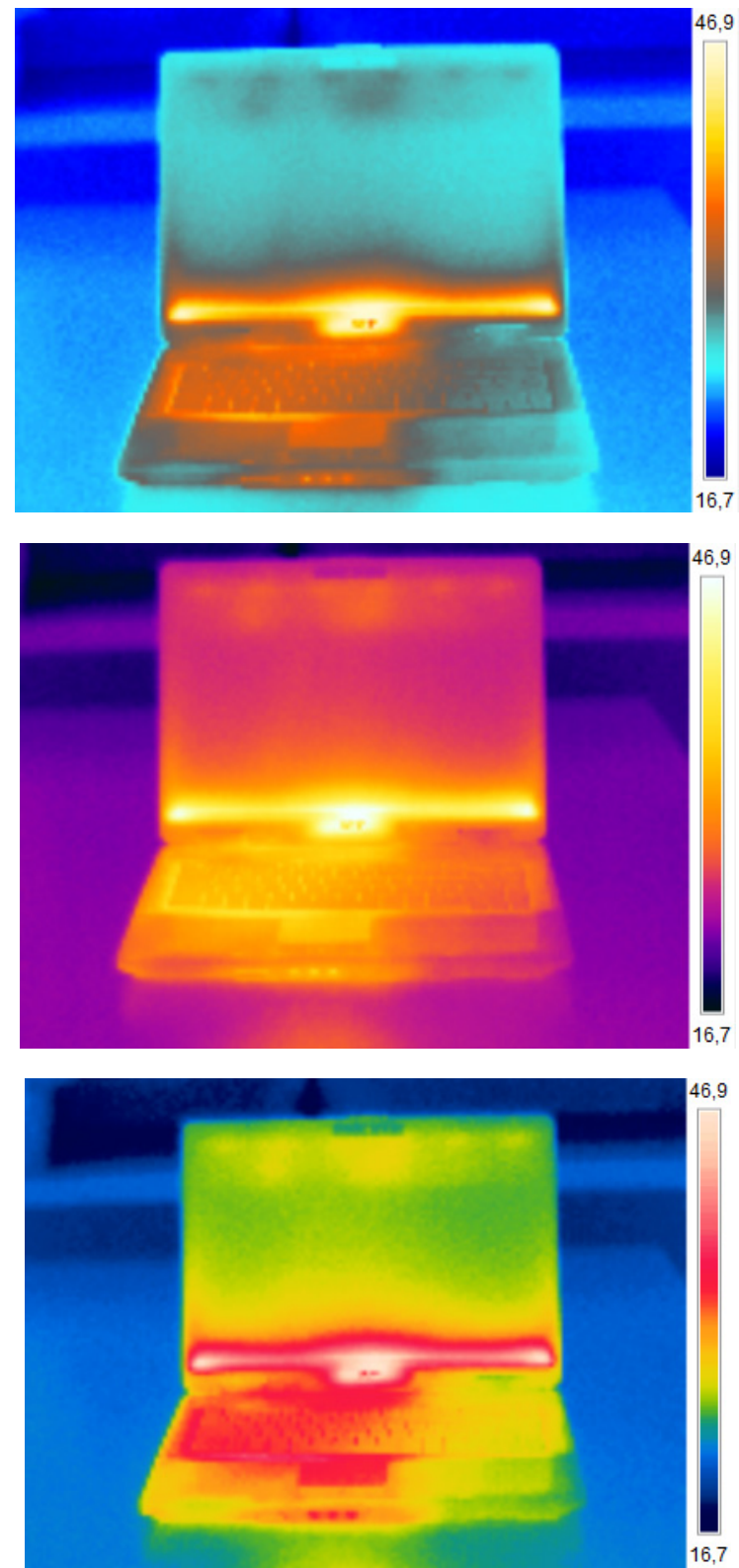

Firure 4. Palette - polar ice, iron, rainbow

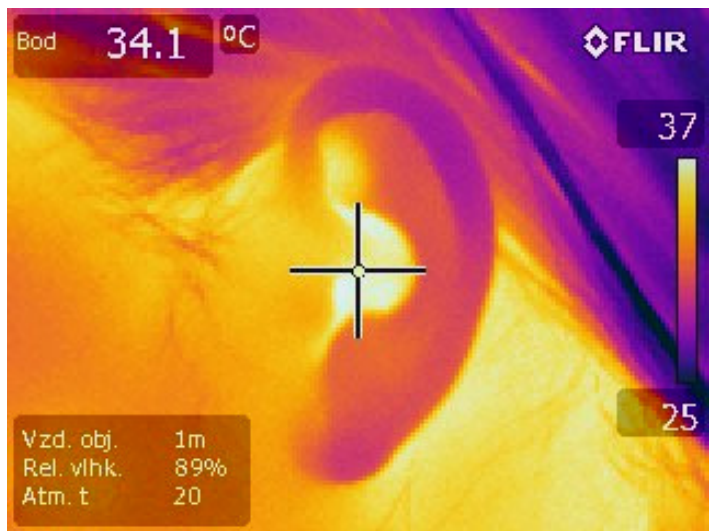




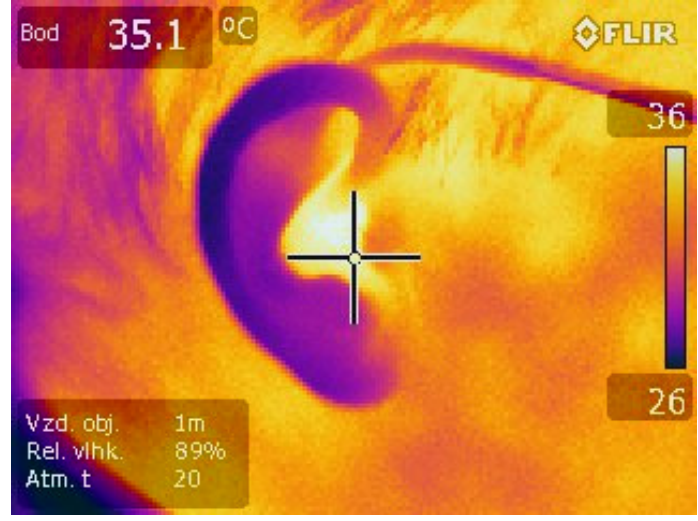

Figure 5. Thermogram of two different people earlobes

- Culinary physics

- linked to the topics: transport of heat, thermal conductivity - we can show the process of liquids heating with gas cookers, induction hobs. It is interesting to observe thermo gram during ice cubes melting in liquids of different density (linked to environmental issues - global warming, melting glaciers).

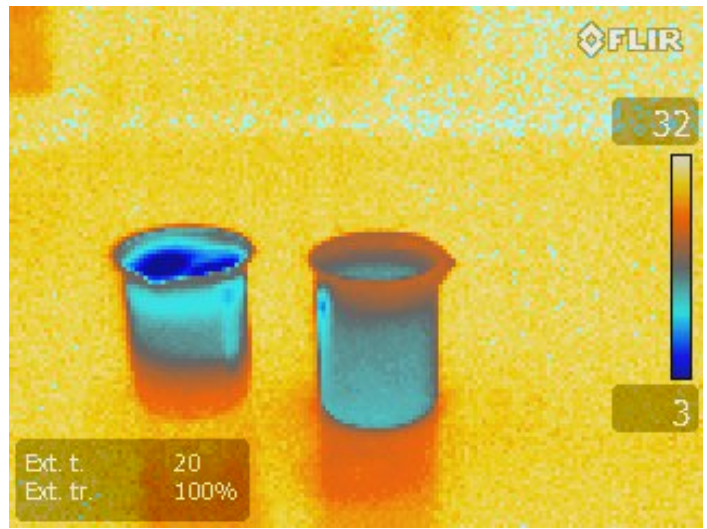

Figure 6. Thermogram of melting ice cubes

In the left beaker is a brine, in the right one is pure water. After adding an ice cube into the beakers, in the left one a layer of cold water can be seen, in the right beaker the whole water is getting cold.

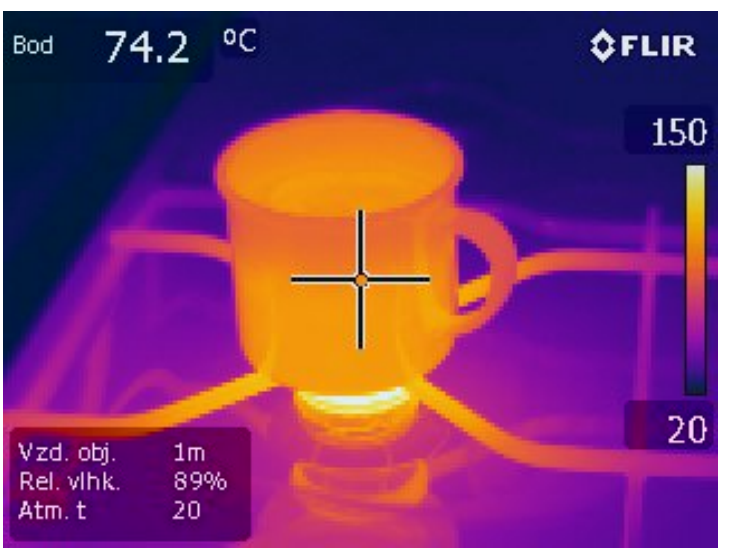

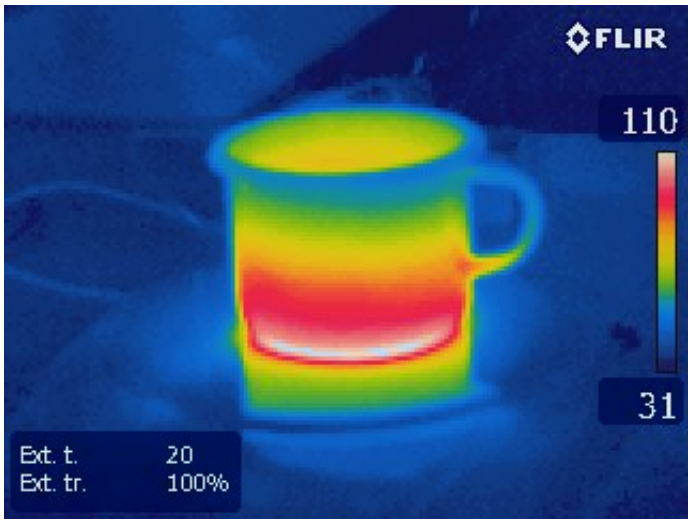

Figure 7. Thermogram of heating water

Heating water with a gas cooker - the pot so as the surroundings is getting hot. Heating with the induction hobonly the liquid in the pot changes the temperature.

- Environmental issues

- thermal imager can detect errors in solar panels.

Damaged cells can cause abnormal heating - and therefore they can cause a fire. In addition, damaged cells can cause substantial loss of performance of the whole system (the whole module strings).
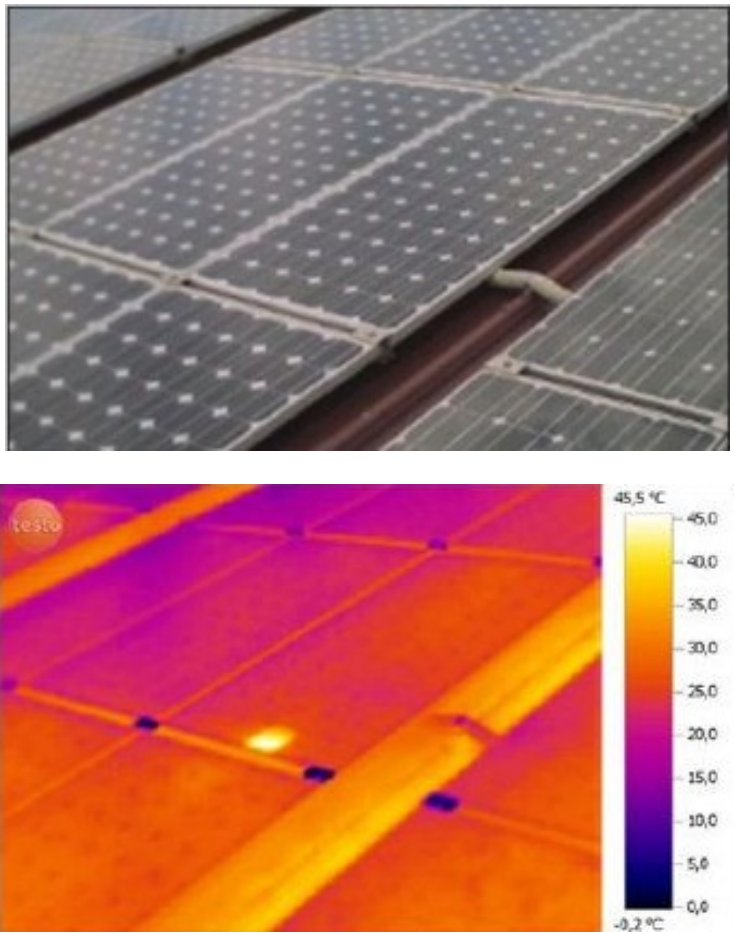

(http:/www.pro-pasiv.cz/diagnostika/termovize-ve-fotovoltaice/)

Figure 8. Defect in a solar panel

\section{USB microscope and its use}

Universal serial bus (USB) - microscope can be connected to a personal computer, a laptop or a tablet and observe objects in their live image, capture images, save them in the format and later work with them. Observation is simpler than with a light microscope and for the normal school 
experimental environment it has sufficient magnification. Objects that can be observed have dimensions from dozens to thousands of microns. Within the module Physics and criminology we can use this microscope to analyse fibres and hair, observe small objects found at the „crime scene“. For teaching optics it is possible to demonstrate the mixing of colours - visualize sub - pixels.
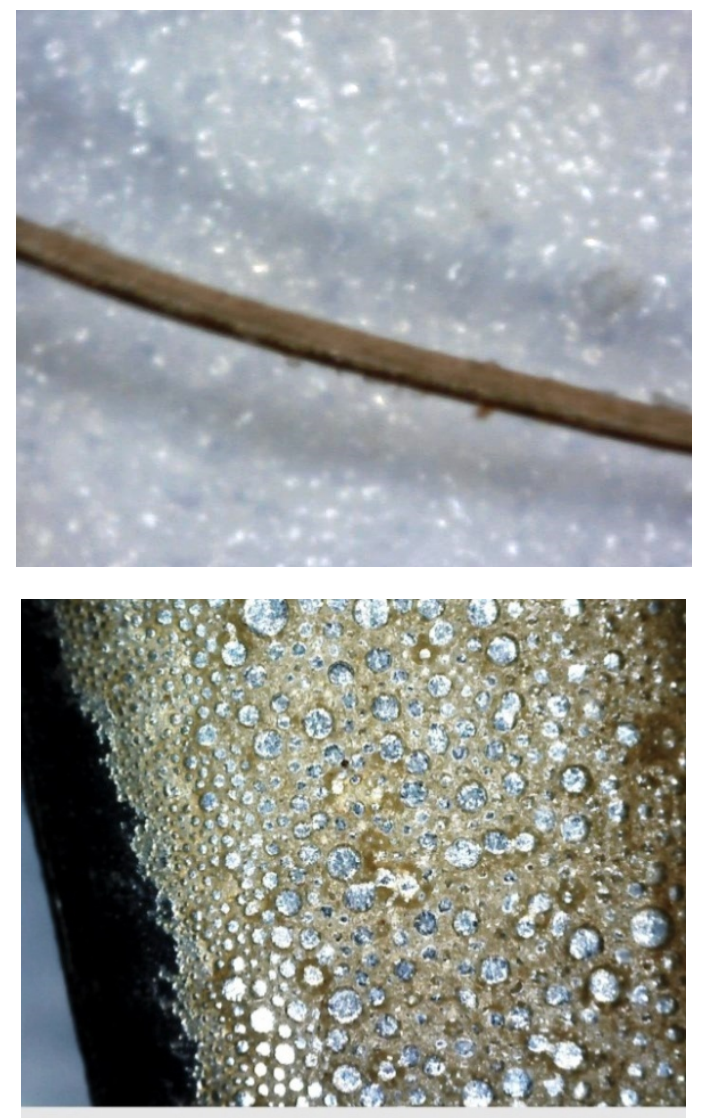

Figure 9. USB microscope - hair and instant coffee

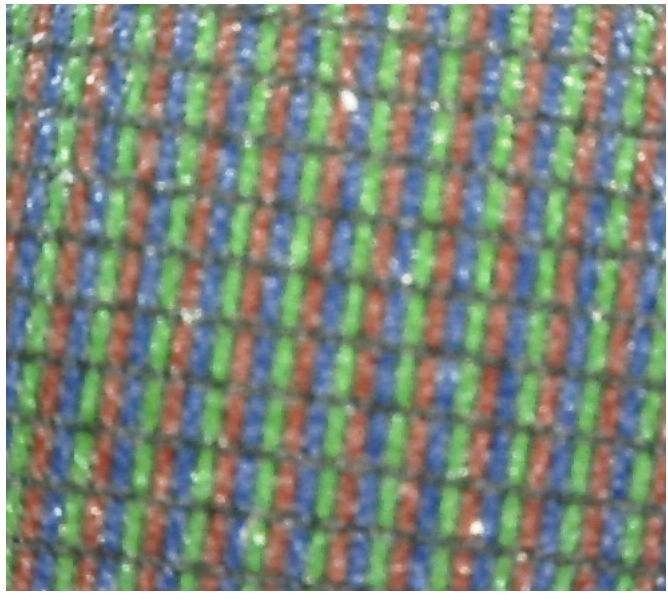

Figure 10. USB microscope - RGB sub pixels

\section{Conclusions}

The outcomes of our research have confirmed that students are motivated to study physics when they can use modern information technology, computers, internet, mobile phones. The majority of schools are good equipped with multimedia. We have found out that teachers use these multimedia rarely; they are not able to take advantage of this teaching aids. Reason for it can be lack of skills and unwillingness to learn something new. We tried to design a variety of activities, where these devices could be effectively and meaningfully used. The process of learning physics we made more attractive and thus contributing to the acquisition of competences defined by the school curriculum. The new Gen Z cannot live without digital technology, but they are not interested how it works. Technology is only a tool for them. When we will achieve better results in the educational process, it is necessary to educate in-service so as pre-service teachers the new approach in teaching and learning science. It is necessary to teach them creativity, exploration skills and understanding of natural phenomena. The activities mentioned above will help to improve the success of teaching and learning science.

\section{Acknowledgements}

The paper is supported by the project OPVK CZ.1.07/2.2.00/28.0182.

\section{REFERENCES}

[1] R. Holubová, R. (2013). Innovations in physics' teacher education. Proceedings of The International Conference on Physics Education, Active learning - in a changing world of new technologies, ICPE-EPEC, 459-466, Prague, 2013.

[2] R. Holubová, P. Keprtová. Repetitorium High School Physics. VUP Olomouc, 2012.

[3] A. Ivanova, A. Smrikarov. The new generations of students and the future of e-learning in higher education. International conference on e-learning and the knowledge society e-Learning '09. 2009.

[4] T. Janík et al. The Power of Video Studies in Investigating Teaching and Learning in the Classroom. Waxmann, Münster, Empirische Bildungsforschung, 2009.

[5] K. MacLeod. Physics Education and STSE: Perspectives From the Literature, European J of Physics Education 4, 86 - 94, 2013.

[6] P. Trunk. Generation $Z$ will revolutionize education On-line available from

[7] http://blog.penelopetrunk.com/2011/03/30/generation-z-will-r evolutionize-education/.

[8] M. Prensky. Digital natives, digital immigrants. From On the Horizon (MCB University Press, 9 (5), 2001.

[9] C.P. Schofield, S. Honoré. Generation Y and learning. The Ashridge Journal Generation $\mathrm{Y}$ and Learning. Winter 
2009-2010.

[10] I. Stioca, S. Moraru, C. Miron. Concept maps, a must for the modern teaching-learning process. Romanian Reports in Physics, 63, 567-576, 2011.

[11] D.Tapscott, Grown Up Digital: How the Net Generation is Changing Your World, McGaaw Hill, New York, USA, 2008.

[12] J. Zounek, K. Sedova. Učitelé a technologie. Mezi tradičním a moderním pojetím. Brno: Paido, 2009.

[13] PISA 2012 Results in Focus. OECD 2014. On-line available from

http://www.oecd.org/pisa/keyfindings/pisa-2012-results-over view.pdf.

[14] Education views. On line available from http://education.qld.gov.au/projects/educationviews/index.ht $\mathrm{ml}$. 